Volume 08, Nomor 03: $182-185$

Desember 2019

\title{
Deskripsi Cacing Tanah genus Polypheretima pada Beberapa Tipe Habitat di Gunung Tompotika, Sulawesi Tengah
}

\section{(Description of Earthworms genus Polypheretima on Some Types of Habitat in Mt. Tompotika, Central Sulawesi)}

\author{
Hartina $^{1 *}$, Mihwan Sataral ${ }^{2}$, Nurmasita Mambuhu ${ }^{2}$, F. Fahri $^{1}$ \\ 1 Jurusan Biologi, Fakultas MIPA Universitas Tadulako JI. Soekarno Hatta km 9 Tondo, Palu 94117, Sulawesi Tengah, \\ Indonesia. \\ ${ }^{2}$ Program Studi Agroteknologi, Fakultas Pertanian, Universitas Tompotika, Luwuk 94715, Sulawesi Tengah, Indonesia.
}

Keywords: Earthworms, Polypheretima, Tompotika Mount, Central Sulawesi

Keywords: Cacing tanah, Polypheretima, Gunung Tompotika, Sulawesi Tengah

* Coresponding Author : hartinakoyang.dj@gmail.com (ph/fax: +62-451-97896)

\begin{abstract}
Abstrak
Penelitian ini bertujuan untuk mendeskripsi cacing tanah genus Polypheretima pada beberapa tipe habitat di Gunung Tompotika, Sulawesi Tengah. Penelitian ini dilakukan dari bulan Februari sampai Mei 2019. Pengambilan sampel dilakukan di tiga plot dengan berbagai tipe habitat, yaitu habitat Hutan Pinus Terbakar (HPT), habitat Hutan Primer (HP) dan habitat Hutan Sekunder (HS). Pada masing-masing habitat ditentukan sebanyak 1 plot dengan ukuran $30 \mathrm{~m} \times 30 \mathrm{~m}$. Setiap plot terdapat 9 titik pengambilan sampel dengan ukuran yaitu $1 \mathrm{~m} \times 1 \mathrm{~m} \times 30 \mathrm{~cm}$ (kedalaman) dan jarak antar titik pengambilan sampel yaitu $10 \mathrm{~m}$. Pada masing-masing habitat ditemukan spesies Polypheretima sp. genus Polypheretima dari family Megascolicidae. Spesies ini tergolong ke dalam kelompok Polypheretima elongata species complex dengan karakter posisi lubang spermathecae di intersegment 5/6/7 dan testis berada di segmen X-XI atau holandric.
\end{abstract}

\begin{abstract}
This study aim describe the genus Polypheretima earthworm in several habitat types on Tompotika Mount, Central Sulawesi. This research was conducted from February to May 2019. Sampling was carried out in three plots with various habitat types, namely Burned Pine Forest habitat (BPF), Primary Forest habitat (PF) and Secondary Forest habitat (SF). In each habitat determined 1 plot with a size of $30 \mathrm{~m}$ $\times 30 \mathrm{~m}$. Each plot has 9 sampling points with the size $1 \mathrm{~m} \times 1 \mathrm{~m} \times 30 \mathrm{~cm}$ (depth) and the distance between sampling points is $10 \mathrm{~m}$. In each habitat was found species Polypheretima sp. genus Polypheretima from family Megascolicidae. This species is belonging to Polypheretima elongata species complex with characters of the spermathecae in intersegment $5 / 6 / 7$ and testes in segments X-XI or holandric.
\end{abstract}

\section{Latar Belakang}

Cacing tanah merupakan kelompok hewan filum Annelida kelas Oligochaeta, dengan ciri tubuh memiliki cincin (Annulus) (Edwards and Lofty, 1977). Cacing tanah tergolong ke dalam kelas Oligochaeta yaitu Annelida yang memiliki karakter sedikit chaeta yaitu struktur berbentuk rambut yang berguna memegang substrat dan bergerak, prostomium yang terletak di bagian ujung anterior dan memiliki clitellum (di belakang prostomium). Clitellum merupakan daerah penebalan segmen yang muncul pada bagian tertentu saat cacing mencapai tahap dewasa (Stephenson, 1923). Pada 
setiap segmen cacing tanah mempunyai organ seperti bagian reproduksi, otot, dan pembuluh darah. Segmen tersebut tetap berhubungan satu sama lain dan terkoordinasi (Rusyana, 2011).

Distribusi cacing tanah kelompok Pheretima tersebar sangat luas di Asia Tenggara termasuk di Indonesia (Easton, 1979). Khusus di Sulawesi, jumlah cacing tanah yang telah dilaporkan sebanyak 19 spesies yang tergolong dalam lima genus yaitu Polypheretima, Planapheretima, Amynthas, Metaphire dan Pithemera (Perrier, 1872; Beddard and Fedard, 1895; Benham, 1896; Michaelsen 1891, 1899; Fahri et al., 2017 dan Fahri et al., 2018).

Sejauh ini, 8 spesies Polypheretima yang dilaporkan dari Sulawesi yaitu Polypheretima elongata (Perrier, 1872) dikoleksi dari bagian Tenggara Sulawesi, $P$. everetti (Beddarb \& Fedarb, 1895) dikoleksi dari Bagian Utara dan Barat Sulawesi, P. phacellotheca (Michaelsen, 1899) dikoleksi dari bagian Timur Laut Sulawesi, $P$. stelleri (Michaelsen, 1891) dikoleksi dari Lembah Bone dan Matinang Sulawesi, dan empat antaranya dikoleksi di Sulawesi Tengah, yaitu $P$. cokelat dan $P$. sahlani dikoleksi di Desa Tongoa, Taman Nasional Lore Lindu, $P$. elongatoides dikoleksi dari Hutan Sekunder Cagar Alam Pangi Binangga, dan P. kalimpaensis dikoleksi di Hutan Sekunder dekat Danau Kalimpa'a, Taman Nasional Lore Lindu (Fahri et al., 2017).

Tulisan ini melaporkan satu jenis Polypheretima dari beberapa tipe habitat di Gunung Tompotika, Sulawesi Tengah. Sehingga dapat menambah informasi mengenai distribusi cacing tanah dari genus Polypheretima di Sulawesi.

\section{Bahan dan Metode}

Alat yang digunakan pada pengambilan sampel yaitu sekop/cangkul, meteran, tali rafiah dan pancang, botol sampel, GPS (Global Positioning System) dan kamera, serta alat penunjang laboratorium yaitu mikroskop stereo, cawan petri, papan bedah, alat bedah, pipet tetes, pinset dan jarum pentul. Bahan yang digunakan yaitu formalin $2 \%$ dan $4 \%$.

Lokasi pengambilan sampel dilakukan pada beberapa tipe habitat di Gunung Tompotika yang terdiri dari tiga habitat yaitu Hutan Pinus Terbakar (HTP), Hutan Primer (HP) dan Hutan Sekunder (HS). Pengambilan sampel menggunakan teknik purposive sampling atau teknik pengambilan sampel dengan pertimbangan dan tujuan tertentu yaitu dengan melihat kotoran cacing tanah (casting) pada permukaan tanah yang lembab dan ditutupi tajuk atau kanopi pohon. Masing-masing habitat ditentukan sebanyak 1 plot dengan ukuran $30 \times 30 \mathrm{~m}$ dengan kedalaman $0-30 \mathrm{~cm}$.

Sampel diidentifikasi di Laboratorium Biosistematika Hewan dan Evolusi Jurusan Biologi FMIPA UNTAD menggunakan buku/kunci identifikasi pada tingkat genus dan spesies berdasarkan Michaelsen (1934), Sims and Easton (1972), dan pada tingkat spesies berdasarkan Perrier, 1872; Beddard and Fedard, 1895; Benham, 1896; Michaelsen 1891, 1899; Easton 1976, 1979; Fahri et al., (2017); Fahri et al., (2018).

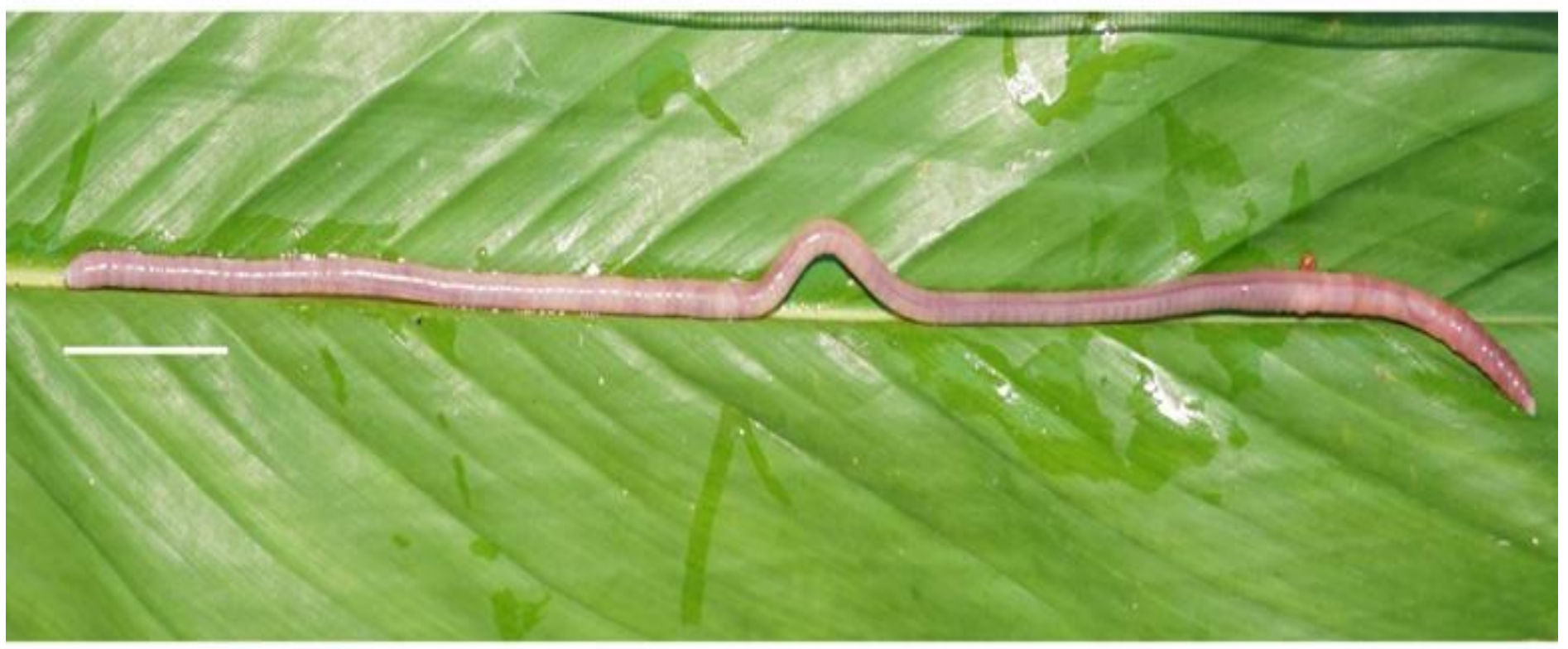

Gambar 1. Polypheretima sp. (Spesimen hidup). Skala bar= $20 \mathrm{~mm}$. 


\section{Hasil dan Pembahasan}

Berdasarkan hasil penelitian yang dilakukan pada beberapa tipe habitat yaitu Hutan Pinus Terbakar (HPT), Hutan Primer (HP) dan Hutan Sekunder (HS) ditemukan satu spesies cacing tanah yang tergolong ke dalam genus Polypheretima family Megascolicidae pada masing-masing habitat.

Polypheretima sp. Karakter. Ukuran sedang, panjang 55-235 mm, diameter 0,3-0,8 $\mathrm{mm}$ dan jumlah segmen 80-220. Prostomium prolobous. dorsal pore terdapat di segmen 12/13. Lubang spermathecal kecil dan tidak terlihat jelas, lateroventrally, berpasangan pada intersegment 5/6/7.

Tidak terdapat spermathecae. Male porophores berukuran sedang dan menonjol, lokasi male pores berada di dalam lubang kopulasi di segmen XVIII. Genital markings berukuran kecil, pada setal ring, berpasangan (jarang tidak berpasangan) pada segmen XIX-XX, jarang di segmen XXI. Testis berada pada segmen $\mathrm{X}-\mathrm{XI}$ atau holandric.

Spesies ini digolongkan ke dalam Polypheretima elongate species-complex (Easton, 1976). P. elongata species complex ditandai dengan male pores yang dangkal, berada di dalam kantong kopulasi dengan sedikit kelenjar glandula di dalamnya. Jumlah lubang spermathecal berpasangan di setiap baterry yaitu 5/6 dan/atau 6/7. Tipe testis holandric. Genital markings post-clitelar, satu pasang per segmen, pre-setal sederhana dekat garis male pore (Easton, 1979). Spesies ini ditemukan di habitat Hutan Pinus Terbakar (HTB), Hutan Primer (HP) dan Hutan Sekunder (HS), pada permukaan tanah yang lembab pada kedalaman 0$30 \mathrm{~cm}$ dan beberapa spesimen ditemukan di bawah akar pohon dan berdekatan dengan pohon yang mengalami pelapukan.

Satu jenis cacing tanah yang ditemukan dalam penelitian ini, memiliki lubang spermathecal di segmen $5 / 6 / 7$, tetapi tidak terdapat spermathecal dan setae 4273 pada segmen VII. Berdasarkan karakter di atas, jenis tersebut berbeda dengan jenis yang pernah dilaporkan sebelumnya di Sulawesi, seperti Polypheretima elongata (Perrier, 1872), P. stelleri (Michaelsen, 1934), P.everetti (Beddard \& Fedarb, 1895), P. phacellotheca (Michaelsen, 1899), P. cokelat, P. sahlani, P. kalimpaensis dan P. elongatoides (Fahri et al., 2017). Selain itu, satu spesies tersebut berbeda dengan kelompok Polypheretima elongata species complex dari luar pulau Sulawesi seperti $P$. kinabaluensi (Beddard \& Fedarb, 1895). Polypheretima elongata species-group di
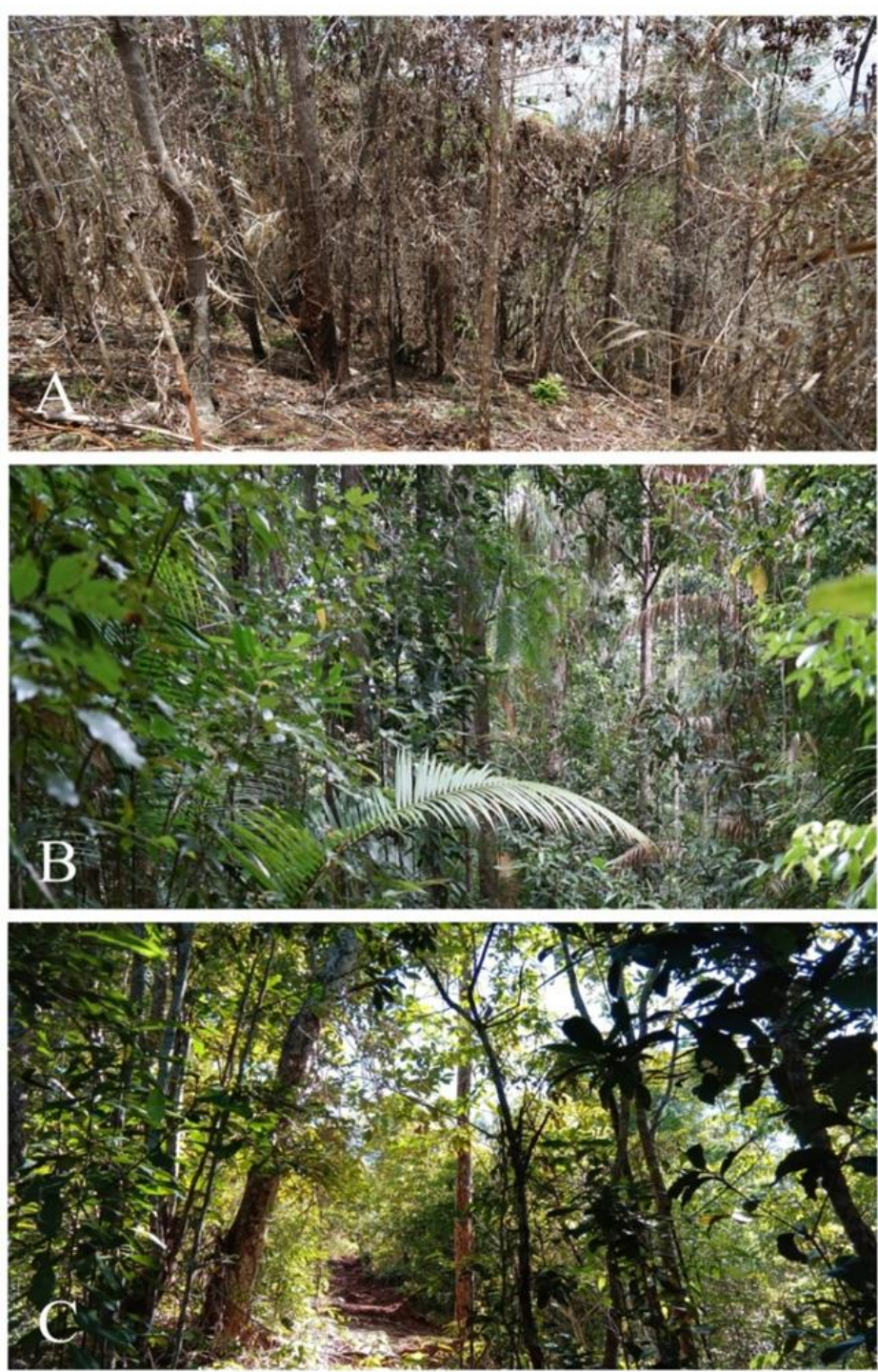

Gambar 2. Habitat cacing tanah. A. Hutan Pinus Terbakar, B. Hutan Primer, C. Hutan Sekunder.

tandai dengan male pores yang dangkal, berada di dalam kantong kopulasi dengan sedikit kelenjar glandula di dalamnya. Jumlah lubang spermathecal berpasangan di setiap battery yaitu 5/6 atau 6/7 atau 5/6/7. Tipe testis holandric. Genital markings post-cliteral, satu pasang per segmen, pre-setal sederhana dekat garis male pore (Easton, 1979). Berdasarkan perbedaan ciri morfologi dan anatomi, maka diduga spesies ini adalah jenis yang belum teriidentifikasi sebelumnya.

\section{Ucapan Terima Kasih}

Kami mengucapkan terima kasih kepada Bapak Munawir Kunjae selaku Kepala Desa Sampaka yang telah memberikan izin untuk mengambil sampel di kebun menteh masyarakat, kepada Dzikri Nurdiansyah, 
Armaludin Embi Karim dan Fadly Djawaba sebagai pendamping lapangan yang mengetahui kondisi Gunung tersebut, Kepada Bapak Mihwan Sataral M.Si, Cipta Afrilianti, Zarina Djusman, Reza Rizaldi, Jusman dan Moh. Sucipto Suharman yang telah membantu selama pengoleksian sampel di lapangan. Kepada Nur Tasbih dan Dewi Santika yang telah membantu saat proses identifikasi sampel di Laboratorium.

\section{Daftar Pustaka}

Beddard F. E., and Fedard, S. M., 1895, On some Perichaetidae from the Eastern Archipelago collected by Mr. Everett. Annals and Magazine of Natural History, Series 6, (16): 69-73.

Benham WB., 1896, Some Earthworms from Celebes. Annals and Magazine of Natural History series 6, 18: 429-448.

https://doi.org/10.1080/00222939608680484

Easton, E. G., 1976, Taxonomy and distribution of the Metapheretima elongata spesies complex of IndoAustralasion (Megascolecidae: Oligochaeta). Bulletin of the British Museum (Natural History) Zoology, 30: 31-53.

Easton, E. G., 1979, A Revision of the 'acaecate' aerthworms of the Pheretima group (Megascolecidae: Oligochaeta). Bulletin of the British Museum (Natural History) Zoologi, (35): 1-128.

Edwards, C. A., and Lofty, J. R., 1972, Biology of earthworm. Chapman \& Hall. London. John Wiley \& Sons. New York. 283 pp.

Edwards, C. E., and Lofty, J. R., 1977, Biology Of Earthworm. $2^{\text {nd }}$ edn. London. Chapman \& Hall. pp.333

Fahri, Amaliah R., Annawaty, and Nguyen A. D., 2017, The Earthworm genus Polypheretima Michaelsen,
1934 (Annelida: Clitellata: Megascolecidae) From Sulawesi, Indonesia, with Descriptions of Four New Species. Journal of Raffles Bulletin of Zoology, 65: 559-573.

Fahri F., Amaliah R., Suryobroto B, Atmowidi T, and Nguyen A. D., 2018, Three new "caecate" earthworm species from Sulawesi, Indonesia (Oligochaeta, Megascolecidae) ZooKeys, 805: 1-14.

Michaelsen W., 1891, Oligochaeten des Naturhistorischen Museum in Hamburg. IV. Jahrbuch der Hamburgischen Wissenschaftlichen Anstalten 8: 1-42.

Michaelsen, W., 1899, Terricolen von verschiedened Gebieten der Erde. Mittheilungenausdem Naturhistorischen Museum in Hamburg, 16: 3122.

Michaelsen, W., 1934, Oligochaeta from Sarawak. Quarterly Journal of Microscoporal Science, 77: 147

Perrier E., 1872, Recherchespoue server 1l'histoire des Lombricins terrestres. Nouv. Archs du Museum Histoire naturelle, Paris 8: 5-198.

Rusyana., 2011, Zoologi Invertebrata. Jakarta: Erlangga Press. 281 hal.

Sims, R. W., and Easton. E. G., 1972, A numerical revision of the earthworm genus Pheretimaauct. (Megascolecidae: Oligochaeta) with the recognition of new genera and an appendix on the earthwormscollected by the Royal Society North Borneo Expedition, Biological Journal of the Linnean Society, 4 (34): 169-268.

Stephenson, J., 1923, Oligochaeta, In. Shipley, A. E. and Scott, H. (Eds.) The Fauna of British India Including Ceylon and Burma., London: Taylor \& Francis Press. pp 5. 